LA W RENCE LIVERMORE NATIONAL LABORATORY

DNA Extraction by

Isotachophoresis in a Microfluidic Channel

S. J. Stephenson

August 12, 2011 
This document was prepared as an account of work sponsored by an agency of the United States government. Neither the United States government nor Lawrence Livermore National Security, LLC, nor any of their employees makes any warranty, expressed or implied, or assumes any legal liability or responsibility for the accuracy, completeness, or usefulness of any information, apparatus, product, or process disclosed, or represents that its use would not infringe privately owned rights. Reference herein to any specific commercial product, process, or service by trade name, trademark, manufacturer, or otherwise does not necessarily constitute or imply its endorsement, recommendation, or favoring by the United States government or Lawrence Livermore National Security, LLC. The views and opinions of authors expressed herein do not necessarily state or reflect those of the United States government or Lawrence Livermore National Security, LLC, and shall not be used for advertising or product endorsement purposes.

This work performed under the auspices of the U.S. Department of Energy by Lawrence Livermore National Laboratory under Contract DE-AC52-07NA27344. 


\section{DNA Extraction by Isotachophoresis in a Microfluidic Channel}

\section{The Project}

Biological assays have many applications. For example, forensics personnel and medical professionals use these tests to diagnose diseases and track their progression or identify pathogens and the host response to them. One limitation of these tests, however, is that most of them target only one piece of the sample—such as bacterial DNA—and other components (e.g. host genomic DNA) get in the way, even though they may be useful for different tests. To address this problem, it would be useful to extract several different substances from a complex biological sample—-such as blood—in an inexpensive and efficient manner.

\section{This summer, I worked with Maxim Shusteff at Lawrence Livermore National Lab on} the Rapid Automated Sample Prep project. The goal of the project is to solve the aforementioned

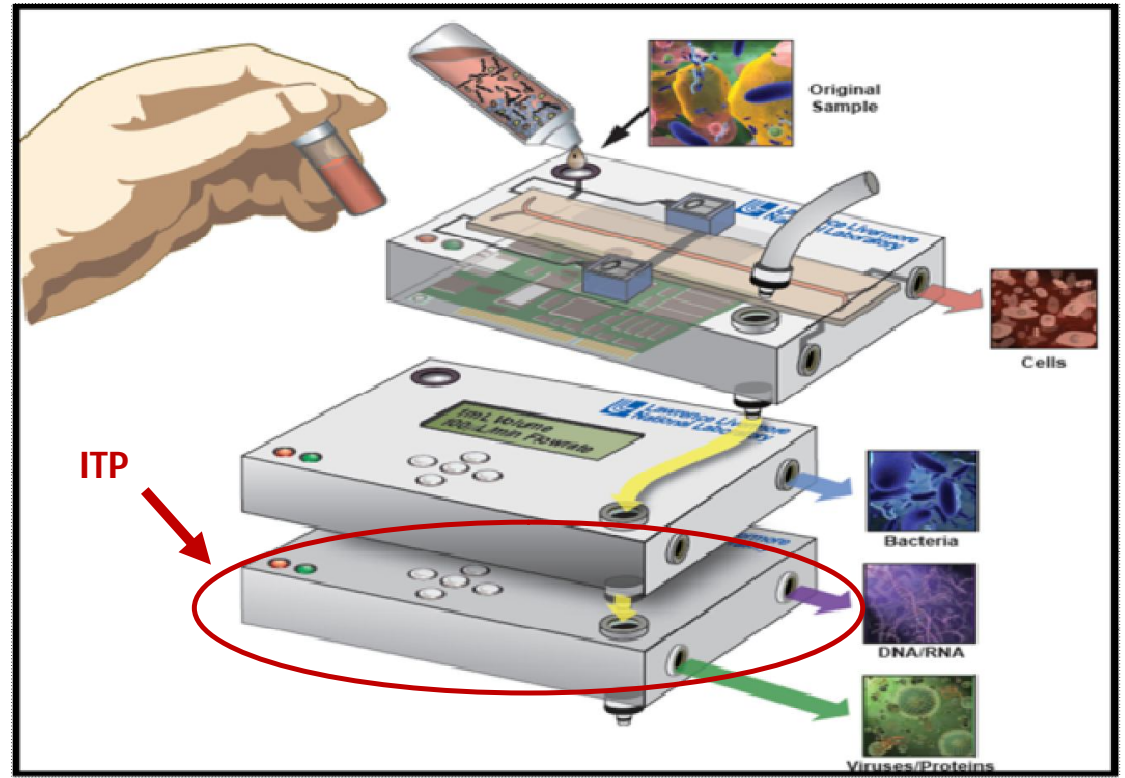

Figure 1 problem by creating a system that uses a series of different extraction methods to extract cells, bacteria, and DNA from a complex biological sample.

Biological assays can then be run on purified output samples. In this device, an

The vision of the Sample Prep project

operator could input a complex sample such as blood or saliva, and would receive separate outputs of cells, bacteria, viruses, and DNA. I had the opportunity to work this summer with 
isotachophoresis (ITP), a technique that can be used to extract nucleic acids from a sample. This technique is intended to be the last stage of the purification device.

Isotachophoresis separates particles based on different electrophoretic mobilities. This technique is convenient for out application because free solution DNA mobility is approximately equal for DNA longer than 300 base pairs in length. The sample of interest—in our case DNAis fed into the chip with streams of leading electrolyte (LE) and trailing electrolyte (TE). When an electric field is applied, the species migrate based on their electrophoretic mobilities. Because the ions in the leading electrolyte have a high electrophoretic mobility, they race ahead of the slower sample and trailing electrolyte ions. Conversely, the trailing electrolyte ions have a slow electrophoretic mobility, so they lag behind the sample, thus trapping the species of interest between the LE and TE streams.

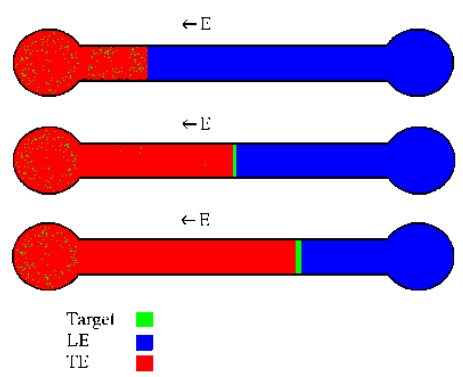

Figure 2 Traditional ITP
In a typical isotachophoresis configuration, the electric field is applied in a direction parallel to the direction of flow. The species then form bands that stretch across the width of the channel. A major limitation of that approach is that only a finite amount of sample can be processed at once, and the sample must be processed in

batches. For our purposes, a form of free-flow isotachophoresis is more convenient, where the DNA forms a band parallel to the edges of the channel. To achieve this, in our chip, the electric field is applied transversely. This creates a force perpendicular to the direction of flow, which causes the different ions to migrate 
across the flow direction. Because the mobility of the DNA is between the mobility of the leading and the trailing electrolyte, the DNA is focused in a tight band near the center of the channel. The stream of DNA can then be directed to a different output to produce a highly concentrated outlet stream without batch processing.

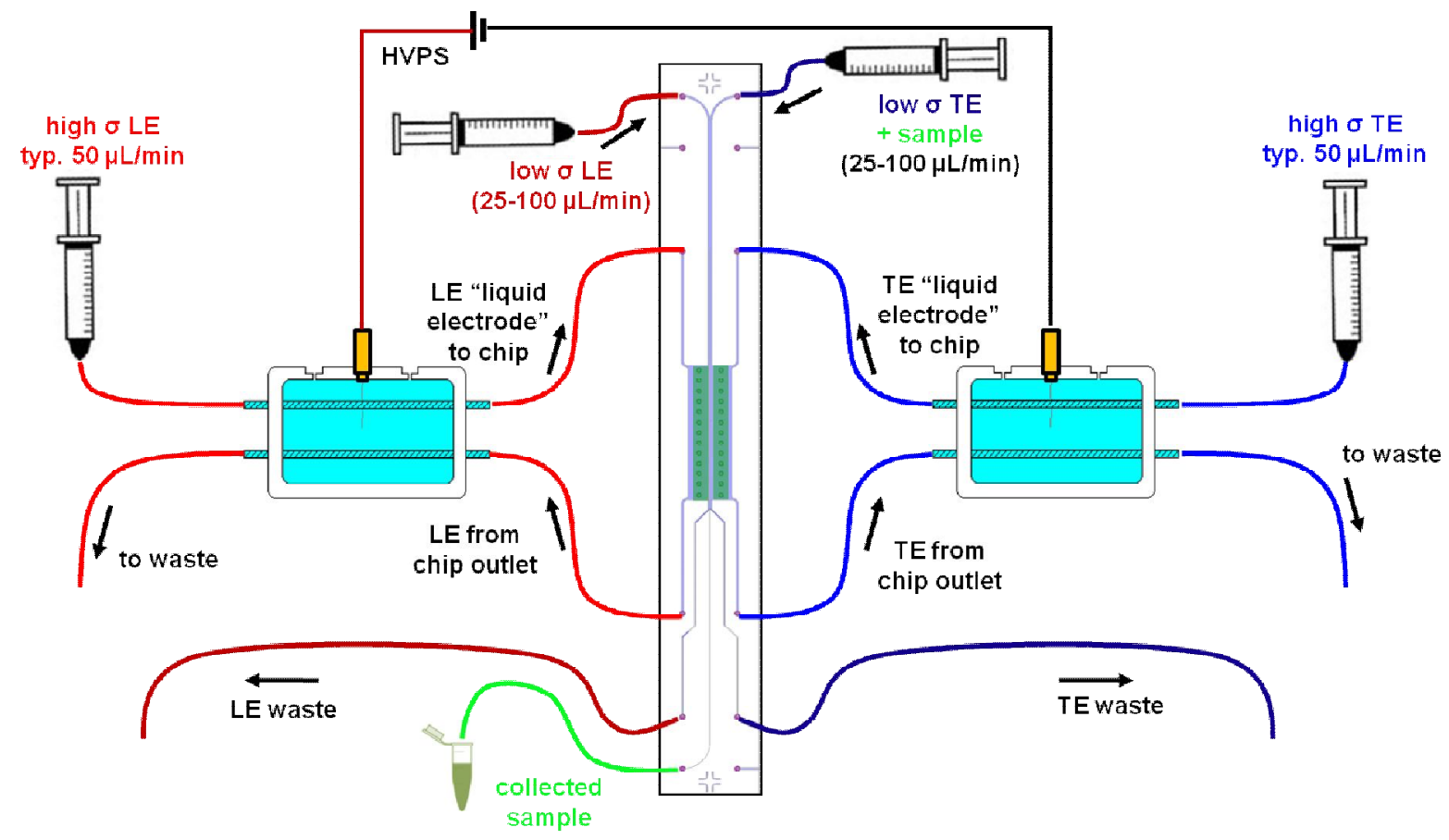

Figure 4

Chip Diagram with Electrode Boxes Depicted in Light Blue

One hurdle that must be overcome for successful ITP is isolating the electrochemical reactions that result from the application of high voltage for the actual process of isotachophoresis. The electrochemical reactions that occur around metal electrodes produce bubbles and $\mathrm{pH}$ changes that are detrimental to successful ITP. The design of the chips we use incorporates polyacrylamide gels to serve as electrodes along the central channel. For our design, the metal electrodes are located away from the chip, and high conductivity buffer streams carry the potential to the chip, functioning as a "liquid electrode." The stream then runs alongside a gel barrier. The gel electrode permits ion transfer while simultaneously isolating the separation chamber from any contaminants in the outer, "liquid electrode" streams. The difference in 
potential from one side of the chip to the other creates an electric field. This field traverses the inner, separation channel, containing the leading electrolyte, the trailing electrolyte, and the sample of interest (DNA).

To increase the ease of use of the chips, a newer chip design has been fabricated. This design has wire electrodes integrated on the chip, rather than elsewhere. To keep the $\mathrm{pH}$ changes and bubbling isolated from the separation channel, the chip contains deeper wells near the electrodes so that the flowing buffer can wash away any gases that form around the electrode. This design is significantly more compact because it eliminates the cumbersome electrode boxes. Eliminating the electrode boxes also decreases the required voltage, making the experiments safer. This happens because when the "liquid electrode" streams travel through small diameter tubing, they lose much of their voltage due to the electrical resistance of the fluid in the tubing. Having the electrodes within the chip ensures that the majority of the voltage applied is dropped over the separation channel. I tested this design for its effectiveness. Recently, my co-worker and I were able to successfully focus DNA in a chip with this new design. This provides a more convenient method for running future experiments. However, since this achievement was recent, my experiments were run on the older design that utilized the "liquid electrodes."

To evaluate the effectiveness of the ITP, the flouresence intensity can be plotted against a position coordinate, where position is measured as distance from one side of the central separation channel. The resulting curve can then be modeled by a Gaussian function. To calculate the focusing efficiency, the fluorescence within two standard deviations of the mean of the

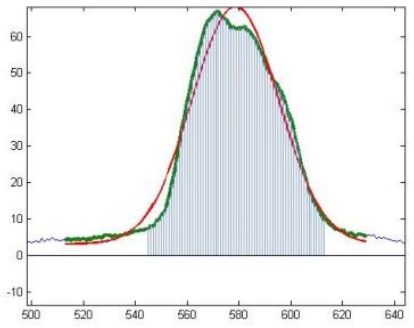

Figure 5 Graph of intensity vs, position Data is in green, Gaussian in Red, and the blue area is the region within $2 \sigma$ 
Gaussian curve is divided by the total fluorescence. This provides a quantitative measure of the focusing efficiency.

\section{Achievements}

For running tests, fluorescein was initially used because it has an electrophoretic mobility similar to that of DNA. I began my summer by running tests on fluorescein, repeating experiments done by my predecessors. Once I had mastered the art of fluorescein isotachophoresis, I progressed to DNA. In order to successfully achieve banding with real DNA, I had to test different buffers to determine the optimal concentrations and conductivity ratios for successful banding. I discovered that the highest

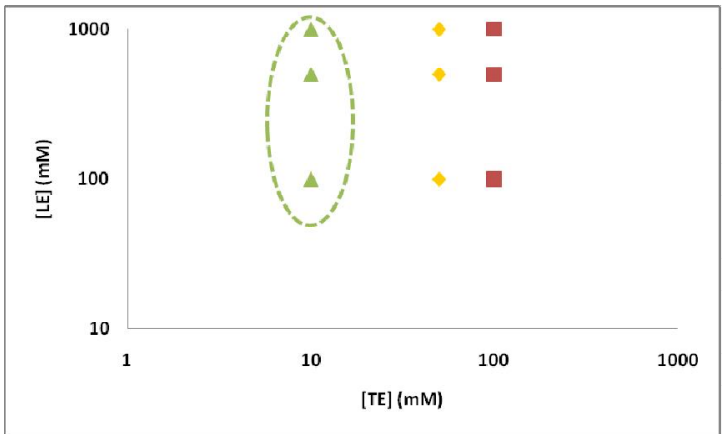

Figure 6

Green area shows region of good banding, yellow indicates diffuse banding, and red designates no banding

concentration of trailing electrolyte that will achieve banding is $10 \mathrm{mM}$ HEPES, with a conductivity of around 300 microsiemens per centimeter. This is far less than the conductivity of blood, so more tests are needed to enable isotachophoresis of real biological samples. As I tested different buffer concentrations, I found that the success of banding is primarily dependent upon the concentration of the trailing electrolyte, and far less upon the concentration of the leading electrolyte. The results are summarized in Figure 6. 


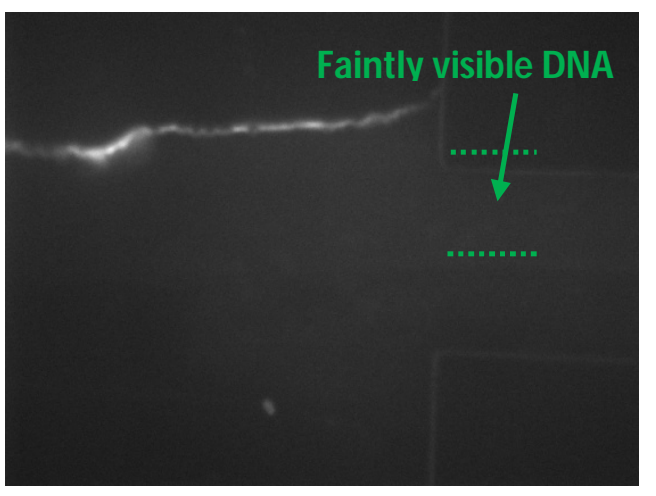

Figure 7

DNA in Chip: Field Off

While more research is still needed, this summer I captured the first images of banded DNA in our setup. The images are consistent with the fluorescein results: the DNA is very spread out while the field is off, spreading throughout the whole trailing electrolyte stream and filtering into the gels on one side and the leading electrolyte stream on the other, as is shown in Figure 7. The DNA is so dispersed in this picture

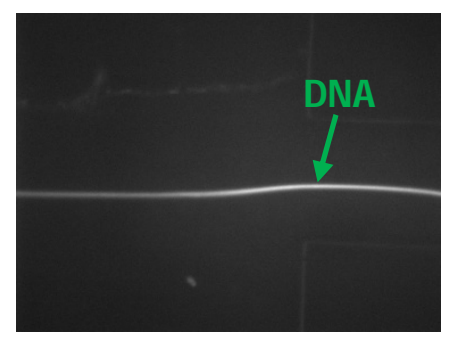

Figure 8 DNA banding: Field On that it is barely visible, and only the very top edge, where the DNA concentrates along the gels is readily apparent. When the electric field is turned on, however, the DNA forms a very thin band near the center of the channel, as shown in Figure 8. This success marked a major milestone for the project. Before my internship, DNA had only been tested once, with poor banding performance; this success was much greater than anything previously achieved.

Before the DNA is visible, it must be stained with fluorescent dye. We used PicoGreen, which is a double-strand intercalating dye. I tested different dilutions in different buffers, and developed a procedure that effectively stains the DNA so that it is visible through a fluorescent filter. Once the DNA was visible under the microscope, I progressed to other experiments such as varying the flowrate. One of the goals for the project is to achieve extraction at high flowrates. This will enable samples to be processed in a timely manner, in a few minutes rather than a few hours. Previously, most of the experiments were performed at 50 microliters per minute. This summer I determined that DNA banding is still visible at $100 \mu \mathrm{L} / \mathrm{min}$, which is the target flowrate for each module within the Sample Prep project. This flowrate will enable fast processing times. 
During my internship, the sponsors of the project visited to receive an update on the progress of the project. I was entrusted with the task of performing a live demonstration of DNA banding. I was able to demonstrate DNA flowing at $100 \mu \mathrm{L} / \mathrm{min}$ that focused in a tight band when the electric field was applied. My successful demonstration along with those of my coworkers helped make for a very positive sponsor visit, and may lead to additional funding for the research effort.

\section{Internship Impact}

Even with so many different, very important projects within its walls, LLNL is very supportive of summer students. The lab sponsored activities such as a movie night to help with networking between students. It organized other events such as a student barbeque to help students meet each other and make connections with full-time lab employees. These events helped me establish connections with other students. I now know engineering students from every region of the country. Having these connections will help me as I continue my education and pursue my career goals.

Lawrence Livermore National Lab offered weekly lectures for the benefit of the students in the DHS HS-STEM program. These lectures provided valuable insight into different areas of research that are connected to homeland security goals. They demonstrated that DHS research covers a very wide spectrum of different disciplines, all the way from regulating nuclear waste, to aerosol mass spectrometry.

Through those lectures, I learned the importance of being able to speak well. The appeal of a lecture was influenced very little by the subject matter; it was entirely dependent upon the presenter. The lecture that most taught me this was one about carbon sequestration. The concept 
of researching carbon dioxide storage did not sound appealing to me, but as I began to listen and learn, I became intrigued by the energy and environmental problems presented in the talk. Topics that I had previously dismissed as boring became interesting. This was due to the presenter's public speaking skills. At the end of the lecture, when answering questions, he said that the people who get the most interesting jobs are those who can speak well and effectively communicate their ideas. I consider this to be very true advice and a special challenge for me, since I am introverted by nature. I am now determined to pursue an education not just in chemical engineering, but to also apply myself to learning to speak.

The lab also offers many weekly lectures on topics such as biology, chemistry, and high density physics. These lectures are very informative and provide a great opportunity to increase my knowledge in areas that are related to my field of study, and to broaden the scope of my learning. I have realized that fields of study do not have rigid boundaries; they begin to overlap and morph together. The goal of bettering public health does not mean that I need to be a doctor or even a biomedical engineer; I can use a chemical engineering degree in biomedical applications.

This internship altered my career goals slightly. Before, I was interested in a graduate degree in bioengineering. However, now I am interested in obtaining a graduate degree in chemical engineering and then using that degree with a biomedical application. At the lab, I was exposed to different people with enormous amounts of knowledge in different fields. If I didn't know the answer to a question, I knew that there would be someone who could give me a welleducated answer. The lab exposed me to a vibrant research community with numerous professionals who constantly motivated me to do my best. I discovered that research is 
challenging and often frustrating, but it is also a lot of fun. This summer has confirmed my interest in research as a career.

\section{Research Ideas}

I think that defending against biological threats continues to be a very important area of research. Bioterrorism remains a threat, and the country needs to have ways of discovering and combating such an attack, should one occur. It is important to research ways of not only identifying a known pathogen, should one be released, but also ways of isolating unknown pathogens so they can be analyzed.

\section{Conclusion}

The experience of an internship at Lawrence Livermore National Lab has been invaluable. I learned that 10 weeks is not enough time to learn everything about a project, but it is enough to make a difference. I was able to learn great amounts of information not only about my project, but also about the many other areas of research at the lab. I listened to lecturers speak about topics that few people even have the opportunity to read about. As I began to apply my knowledge, I was able to make a difference to my project. The internship not only benefitted me greatly; through it I made an impact on an area of research that is important to national security.

\section{Acknowledgements}

I would like to thank Maxim Shusteff and the entire Sample Prep team for all of the valuable input they provided during my internship. I would also like to thank the DHS HSSTEM program for providing me with the funding for my internship. Additionally, I would like 
to thank the Department of Energy and Lawrence Livermore National Lab for hosting me. This work was performed under the auspices of the U.S. Department of Energy by Lawrence Livermore National Laboratory under Contract DE-AC52-07NA27344. 